This is an Accepted Manuscript of an article published by Taylor \& Francis in Small Enterprise Research on 23/02/17, available online:

https://www.tandfonline.com/doi/full/10.1080/13215906.2016.1270227 


\title{
Entrepreneurship Policy: Issues and Challenges
}

\author{
David Smallbone \\ Professor of Small Business and Entrepreneurship \\ Small Business Research Centre \\ Kingston University
}

(Email:d.smallbone@kingston.ac.uk; tel:+447786 096912)

Published as

Smallbone D. (2017) Entrepreneurship Policy: Issues and Challenges, Small

Enterprise Research, pages 201-218, Published online: 02 Feb 2017 


\section{Introduction}

As entrepreneurship has increasingly become a global phenomenon so governments across the globe have paid increasing attention to it, or at least have claimed to have done so. In this context it seems appropriate to take a step back and consider some of the issues raised by what is increasingly becoming a high profile policy target. Whilst entrepreneurship results from the creativity, drive and skills of individuals, rather than from the actions of government, government policies and actions are a key influence on the external environment in which entrepreneurship takes place; in some cases constraining it, in others facilitating it.

Following this introduction in which definitional issues with respect to entrepreneurship policy are considered, the rest of the paper is structured as follows. The next section summarises the case for entrepreneurship policy, followed by the case against. The rest of the paper considers five policy issues: the importance of context; the policy process; the role of evidence based policy; the importance of policy evaluation and public procurement as a policy tool.

In initiating a discussion of entrepreneurship policy and some of the issues that need to be addressed if it is to be effective and appropriate in the future, the first task is to define what is meant by the term entrepreneurship policy. As in many other cases, there is not complete agreement between academics on this issue. On the one hand a relatively narrow definition focuses on those policies specifically targeted at influencing entrepreneurship development (Lundstrom \& Stevenson, 2005). In this case, the question of what constitutes entrepreneurship policy is answered through a list of the types of policy interventions that are likely to promote and support it. These include:-

- The promotion of an entrepreneurship culture and more favourable attitudes towards entrepreneurship

- The integration of entrepreneurship education in schools and at all levels of postsecondary education

- A reduction in the barriers to entry, combined with pro-active measures to make it easier for enterprises to enter the market

- The provision of seed finance to facilitate business creation and subsequent development

- The various types of start-up business support including mentoring programmes, business incubators, designed essentially to increase the number of new businesses and nurture their early development

- Tailored effects to increase the participation in business ownership of underrepresented groups, such as ethnic minorities, women and young people 
In combination, such measures may be taken as an attempt to promote, encourage and support the development of entrepreneurship through various measures which are designed to improve the environment in which entrepreneurship can flourish. In contrast, a more broadly based view of entrepreneurship policy is concerned with the effects of government policies and actions on the development of entrepreneurship whether or not these are specifically aimed at entrepreneurs. Such an approach is best described as focusing on the government policies and actions that impact on the development of entrepreneurship, rather than focusing on policy measures that are specifically targeted at it. The point here, which needs to be stressed, is that whilst a narrowly defined entrepreneurship policy is only ever likely to affect a small minority of entrepreneurs and their businesses, there are a variety of types of policies and actions that government may engage in, which effect the vast majority of businesses. Of course, in practice, there may be a combination of these two interpretations of the importance of entrepreneurship policy with the Lundstrom \& Stevenson (2005) emphasis being particularly appropriate in countries and regions where the level of entrepreneurship is at a low level. This does not negate the importance of active monitoring and review of the wider policy set. This needs to be done regardless of the current level of business start-up or business ownership. This broadly based view is represented by the work of Smallbone \& Welter (2001).

Of course, there are good reasons why one would expect some variation between countries and regions in the types and strengths of policy intervention used, on the basis that the level of entrepreneurship itself can vary considerably between regions and between countries. Indeed the attitude and stance of the population towards entrepreneurs also varies considerably at a regional and national level. In this context one would expect that where the level of entrepreneurship is low, more attention would need to be paid to the types of measures that are designed to promote it.

In the so-called broad view of entrepreneurship policy the central proposition is that the development of entrepreneurship is heavily influenced by the role that government plays in the macro-economic environment in which business is conducted. Of course, this argument applies rather more in mature market economies than it does in developing, or emerging, market economies, but, nevertheless, government policies and actions impact on such indicators as exchange rates and interest rates, which can have major impacts on the environment in which business is conducted.

A second element in the so-called broad view of entrepreneurship policy is where government legislation and regulations can impact on businesses, which it is often argued, has a differential impact on businesses of different sizes (Kitching, 2006) (Van Stel et al, 2007). This is essentially a proportionality effect, with the impact on smaller businesses being stronger than in the case of larger enterprises where there may be an increasing managerial division of labour. This includes specialists taking care of some areas, such as health \& safety, which in a firm of less than 20 employees will typically be one of the many responsibilities of the business owner. The argument here is not that government is 'out to get' the entrepreneur but, more often, the effects of its interventions include effects that are not intended. 
The next influence is through the business tax regime, particularly in the case of economies that are at a lower level of development. For example, if we take the case of the new member states of the European Union these are countries which, in the past, have operated under central planning. In these countries, the employer's responsibility for social security payments in the early years of transformation was penal. The main problem was social security payments which during the Soviet period were the responsibility of state owned enterprises. This meant that when the Soviet Union collapsed many people were left without social security for a period.

From a policy perspective the problem was that there was no accumulated fund that could be used to kick-start the process of establishing a more centralised social security system. So the fund had to be built up from current income. The result was that it was almost impossible for small businesses to operate totally within the law and, at the same time, to be profitable. As a consequence the majority of small businesses were forced into the informal sector for at least part of their activities.

The level of taxation was one problem but another was the frequent changes in tax regimes and taxation systems. In many respects this was understandable given that these countries were finding their way in a market oriented system, in which the role of government had fundamentally changed. But, from a business perspective, the rapid change in the tax regime and the expectations of the taxation authorities meant that, in many cases, businesses found it necessary to employ accountants or taxation specialists in order to be compliant with these very frequent changes. The cost of supporting such staff was unnecessary in the minds of most small business owners; it was also a non-productive activity as far as they were concerned.

\section{The Case for Entrepreneurship Policy}

In most cases public policy aimed at promoting entrepreneurship is based on the premise that if entrepreneurs are to fulfil their longer-term contribution to society and economy, they may need some help particularly at start-up. This includes addressing some of the market failures they experience with respect to key resources such as finance, business information, advice and consultancy and premises. 
Figure 1: Entrepreneurship and Economic Development

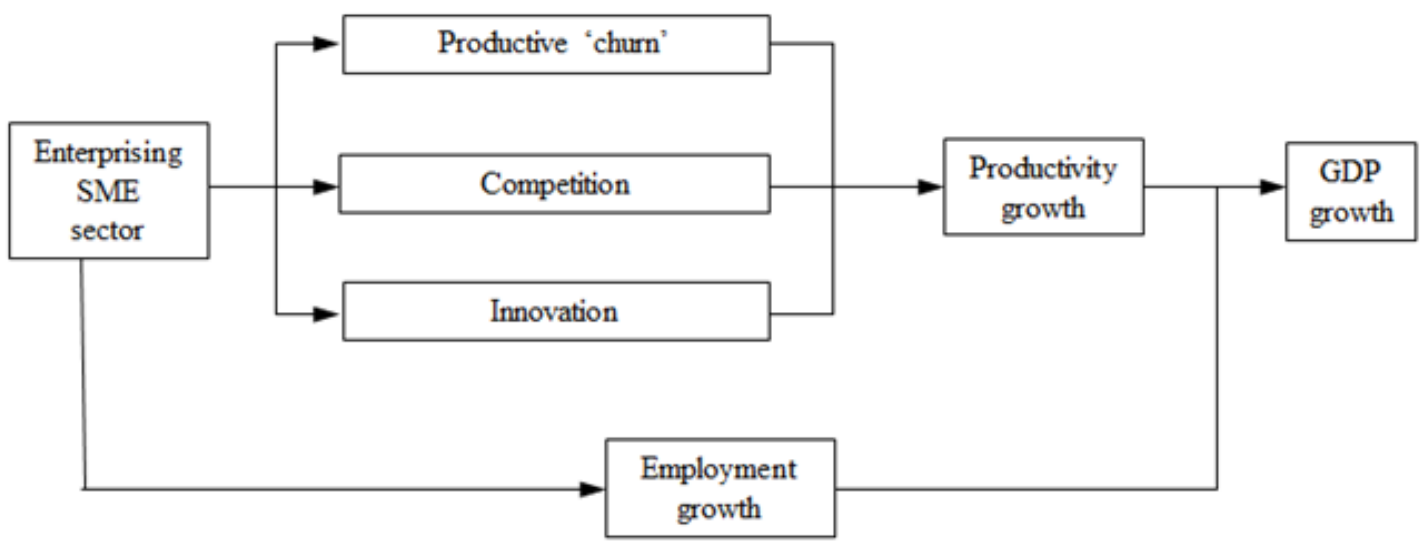

The economic rationale for public policy intervention to support entrepreneurship development is captured in Figure 1. An enterprising SME sector means those SMEs that are growth-oriented. As the diagram shows, productivity is the key element affecting competitiveness. As the diagram also shows, SME growth can impact on GDP in three main ways: firstly through competition with other enterprises, secondly through innovation; and thirdly through what economists call productive churn. This is the relationship between the productivity of businesses leaving the market in comparison with the productivity of new entrants. If the productivity of new firms entering the market is higher than those leaving then there is a net gain in terms of the level of productivity in the economy as a whole.

An additional argument in favour of entrepreneurship policy is to enable the potential contribution of entrepreneurship to social inclusion to be achieved. This is somewhat problematic as much of the evidence base to support the proposition that entrepreneurship reduces social inclusion, whilst intuitively appealing, is not well supported evidence.

One of the underlying themes that run through the paper is the need to recognise the context in which entrepreneurship policy is developed and introduced. This applies in the case for entrepreneurship policy insofar as this is affected by current levels of business start-up; and business growth. It can also be used as part of the argument against maintaining or increasing entrepreneurship policy. This is an argument developed by Professor Bennett who suggests that in the UK for example, most of the market failures that have been used as a justification for policy intervention in the past, have now either been rectified or are close to being rectified. As a consequence it is no longer appropriate to have a comprehensive programme of support for entrepreneurs (Bennett, 2008). 


\section{The Case against Entrepreneurship Policy}

The ineffectiveness of much of entrepreneurship policy is one of the main reasons why it has come under increasing criticism. Clearly the effectiveness of policy in achieving its objectives can be determined by the implementation mechanisms that are used because, no matter how well designed a policy is, if the agents responsible for delivering it do not have the confidence and penetration of the target group it is unlikely that the policy will be effective. Moreover, policy implementation can become unnecessarily complex thereby contributing to confusion in the minds of the target group, particularly in terms of the number of sources of help and advice that are available. If a lack of clarity exists in terms of which agencies are responsible for what, as well as circumstances where the target group lack confidence in the providers of support perhaps because of previous experiences, the policy is unlikely to be effective.

The low level of awareness of public policy measures appears to be a universal phenomenon. Even in countries such as the UK, where the infrastructure for the implementation of public policy with regards to entrepreneurship is reasonably well developed, there are target groups that are difficult to reach by mainstream support agencies. In this regard, there are different models of policy delivery. One is where government organisations are responsible for delivering the support themselves. An alternative model is where the delivery is contracted out, to other organisations, has both advantages and disadvantages. It is usually a method for reducing costs, particularly overhead costs. The contracting-out model can be effective if the agencies that are delivering the contract have strong roots with the target group they are aiming to serve. Examples include different types of ethnic minority group, where a specialist agency in ethnic minority enterprise, is likely to have more penetration of that sector than mainstream agencies.

The evidence available to help assess the effectiveness of public policy is in general fairly limited, even In the UK where some form of entrepreneurship policy has been in existence for many years. Analysis of the period 1999-2009 showed little evidence that entrepreneurship policy has resulted in either an increase in business start-ups or an increase in growth amongst existing firms (Bennett, 2008). This lack of evidence has contributed to an emerging view of the ineffectiveness of entrepreneurship policy mainly, perhaps, because of the ineffectiveness of its implementation. The reasons why implementation often falls short, or is less effective than it should be, includes situations where policy is formed without consideration of implementation issues. Another reason is that there is insufficient consultation with the target group about the methods of implementation. In some cases there are insufficiently clear policy goals and a lack of skill on the part of those responsible for the policy implementation.

This is an area where one must be critical. In the private sector the starting point for the development of a new product or service would include some kind of market research. This might include focus groups where those most affected by the new product would have an opportunity to express their view. In contrast, throughout the world it is extremely rare for policy makers to formally engage with the stakeholders, small business owners about policy 
design and policy delivery. This is one area where there is a need for improvement if the effectiveness of public entrepreneurship policy is to be increased. There is something to be learned from the Chinese in this regard, where a degree of policy experimentation can be detected. This may involve testing a policy approach in a number of cities before the policy is rolled out across the country.

Arshad, Carter \& Mason (2014) argue that a key factor explaining the ineffectiveness of entrepreneurship policy is how it is formulated. The process of policy formulation is seldom visible to those outside government departments and has been largely ignored by previous research. In this context Norin Arshed's ground-breaking work on policy formulation and the policy process warrants further research. Despite the popularity of entrepreneurship policies their effectiveness has been questioned (Curran \& Storey 2002), (Huggins \& Williams 2009), (Williams 2013).

Critics typically attribute the lack of effectiveness of entrepreneurship policy to the way it is implemented. At the same time Scott Shane (2009) has suggested a more fundamental explanation for its lack of effectiveness, namely that it represents bad policy. David Storey (2000) had made a similar point; suggesting that entrepreneurship policies that are currently pursued often lack clear objectives. Recent analysis, however, suggests that bad policy results from the way that it is formulated (Dennis 2011). So, it is fair to say that, hitherto the policy formulation stage of the policy process has not attracted a lot of attention from entrepreneurship and small business researchers. Arshed's research showed that in interviews with senior policy makers they showed awareness of how the formulation process should work ideally, whilst recognising that the reality is somewhat different. Arshed's research opens up new challenges for future research. Firstly, more evidence is needed to better understand the processes involved in entrepreneurship policy formulation; for example, who the key actors are and what the role of ministers and senior civil servants is in this process.

The question of policy effectiveness needs to be considered in relation to the cost involved. There is a need for more research because there have been few attempts to fully assess the costs of entrepreneurship policy to the tax payer. The UK government attempted to do it and in Europe a research project known an IPREG has also sought to do this. However cost benefit analyses of this sort are difficult because of the need to measure benefits and costs that are hidden. Nevertheless, the results of a UK government investigation by the Department of Trade \& Industry in 2003 were staggering. Aggregate expenditure on entrepreneurship policy was estimated to be between $£ 8-£ 10$ billion at a time when expenditure on police services and also on the universities, was slightly lower at around $f 7$ billion in each case. Moreover, the expenditure involved came from a wide range of government departments, not simply the department that was mainly responsible for enterprise policy. Unlike other major spending areas such as the police and universities expenditure on entrepreneurship policy was not the responsibility of a single ministry or department making it more difficult to control. 
The key spending department was the Treasury, where spending on entrepreneurship policy, particularly through tax relief was valued at $£ 2.6$ billion in 2002 and increasing to $£ 3.6$ billion in 2006. The results were surprising; firstly, because of the sums involved, which can be explained by the fact that much of it was in the form of tax relief from other forms of subsidy; and secondly because the organisation mainly responsible for delivering small business policy at the time, namely the Small Business Service only accounted for approximately $2.5-3 \%$ of total expenditure. So, when the ineffectiveness of the policy field is combined with its large cost helps to explain why in recent times there have been a growing number of questions asked about the true value of this policy area.

\section{Key Issues for Entrepreneurship Policy}

\section{Policy Issue 1: Increasing attention should be paid to the context for entrepreneurship policy}

One of the emerging themes in the literature on entrepreneurship in recent times has been a call for a more explicit emphasis on context which, in the case of some theoretical approaches, has been rather neglected hitherto. Context refers to the historical, social, economic and institutional environment and their interrelationship into a complex and unique whole (Welter (2011). However, just as context is important for the study of entrepreneurship, it is also important for a study of entrepreneurship policy. Since the needs, strengths, weaknesses, threats and opportunities facing countries, regions and localities vary, so the context in which entrepreneurship may be seen as a potentially positive influence on the development of these areas also varies. More specifically, the context for entrepreneurship policy includes the current level of entrepreneurship and the trends within it. This is likely to impact on the needs of the region, locality or country with regards to attempts to stimulate more entrepreneurial activity. It is also influenced by the characteristics of these areas which may have an impact on how easy or difficult it is likely for entrepreneurship to take on this role. All these features are important if the polices that are developed and prioritised are to make an effective contribution to economic development of the areas of which they are a part.

In addition, a consideration of context is vital where policy transfer is considered a part of an approach to economic development policy. The potentially controversial nature of this exercise is reflected in the substantial literature that has been devoted to it. Issues that arise include what exactly should be transferred. Is it the concept and/or the method of implementation? Or is it the whole package lock, stock and barrel? The latter approach is unlikely to be effective unless the institutional framework in the recipient region or country is compatible with that in the source area. This applies, not just to the formal institutional frame but also the informal one, in the sense of how these institutions behave.

In this context, and not surprisingly perhaps, attempts to transfer policy from Europe to China have proven to be particularly difficult. This is not altogether surprising in view of the substantial differences between the cultures in terms of their institutional frames. Once small business ownership was made legal in China and, having established a network of loan 
guarantee institutions across the length and breadth of the country, the Chinese government decided to turn its attention to business development services (BDS), partly because entrepreneurs often need help in writing business plans to support their funding applications. So the development of BDS was seen as complementary to the financial interventions. In this context, the Chinese government turned to those parts of the world where the provision of business advice and consulting for small businesses was well established.

This included a number of technical assistance projects, including one that focused on designing a strategy for the provision of SME support in China. The consultancy team working on this project included the author of this paper, whose responsibility was to design a BDS model that could be adapted for cities at different levels of development [Small bone et al, 2008). In order to undertake this task, surveys were conducted with providers of business development services and also with businesses that were potential users of BDS. These surveys were designed and implemented in co-operation with local officials in each city in an attempt to demonstrate an evidence based approach to policy formulation. Some people have argued that China does not need to follow the business support systems that are typically found in mature market economies, such as the UK, the USA and Germany. This is because China has developed informal support systems which are close to the entrepreneur, both in physical distance and also in the way the relationship is perceived by business owners.

Some authors have argued against encouraging China to develop the kind of formal business support services network that has been attempted in many European countries either in the form of Chambers of Commerce or public and semi-public sector agencies, such as Business Link in the UK. However, whilst such methods may have served Chinese businesses well in the past, there is a question as to whether or not these informal institutions are sufficient to meet the needs of an emerging private sector in the future. It is the view of the Chinese government that they are not. Continuing reliance on the informal systems of the past is unlikely to provide enough access to the business services that they need to help them to upgrade their management practices and widen their resource base. This particularly applies in the case of small enterprises.

A subsidised consulting scheme was devised. It was targeted at small businesses which had not previously used external consultants, whether for the development of strategy or more operational matters. The idea is that if the public sector subsidises the first round of consultancy use, and if the consultants delivering the advice and support are vetted and accredited, then there should be double benefit. On the one hand, the market for consulting by small businesses is widened and on the other, there is an increase in the number of consultants who have experience of working with small businesses.

Clearly therefore, the percentage of the total consultancy costs that are subsidised is central to the question of the extent to which the measure incentivises business owners to make use of consultants. This is how such schemes operate in Western countries where this type of measure has proven to be quite successful. However, in China, the financial support from 
central government for a policy such as this is only forthcoming when there are some results. In other words, the financial support is retrospective. Clearly this represents a very different philosophy and is problematic in the case of subsidised consultancy because, in the Chinese model, potential participating businesses do not know what the level of subsidy will be when they are expected to commit to the programme. This uncertainty makes it difficult to recruit small businesses for the programme.

A further example of the difference between the Chinese and Western contexts is with respect to the encouragement of growth in small businesses. In Western countries the principle is the one applied above, namely, to identify businesses that are trying to grow and to offer financial assistance to help them to deal with some of the issues and constraints that they face to help them achieve the growth they seek. By contrast, in China, the financial support appears to take the form of a prize that is given to businesses that achieve growth, once growth has been achieved. From a Western perspective there appears to be little additionality in this model but, instead, a substantial portion of deadweight. Critics may suggest that these differences should have been identified by the consultants from the outset. This may be the case, but on the other hand there were other quite significant differences which were identified and responded

to. The lack of strong centrally organised consultant accreditation system is one example. One might expect the local officials to have pointed out these issues but they did not. More generally one might suggest that transferring policies between contexts with such a wide, cultural and institutional divide will inevitably throw up problems. Clearly, the difference in the nature and behaviour of institutions is at the heart of this.

Another situation where context is important refers to the neighbours of the European Union and, in particular, those that have aspirations to become members of the European Union, such as Albania in the Balkans. (Xheneti \& Kitching 2011) The contextual issue in this case refers to the lack of responsiveness of those responsible for transferring policy to local conditions, the lack of appreciation of the need to identify the strengths and the weaknesses, not just in the economy and the business community, but amongst practitioners and those in government responsible for developing policy. Without this, it is unlikely that the policies that emerge will be well-tuned to the needs of the economy.

\section{Policy Issue No 2: Greater recognition should be given by researchers and practitioners to the importance of the policy process}

The study of public policy typically disaggregates the policy process into a number of components. Figure 2 represents a conceptual model of the policy cycle. The diagram demonstrates that research has the potential to influence the process at any stage, although the nature of the research required may vary. Sutcliffe \& Court summarise the main stages as agenda setting, which refers to the awareness of and priority given to a particular issue; policy formulation, which refers to the ways, options and strategies are constructed; policy implementation, which refers to the forms and nature of policy administration and the activities associated with it; and lastly, monitoring and evaluation of policy. 


\section{Figure 2}

\section{The policy cycle}

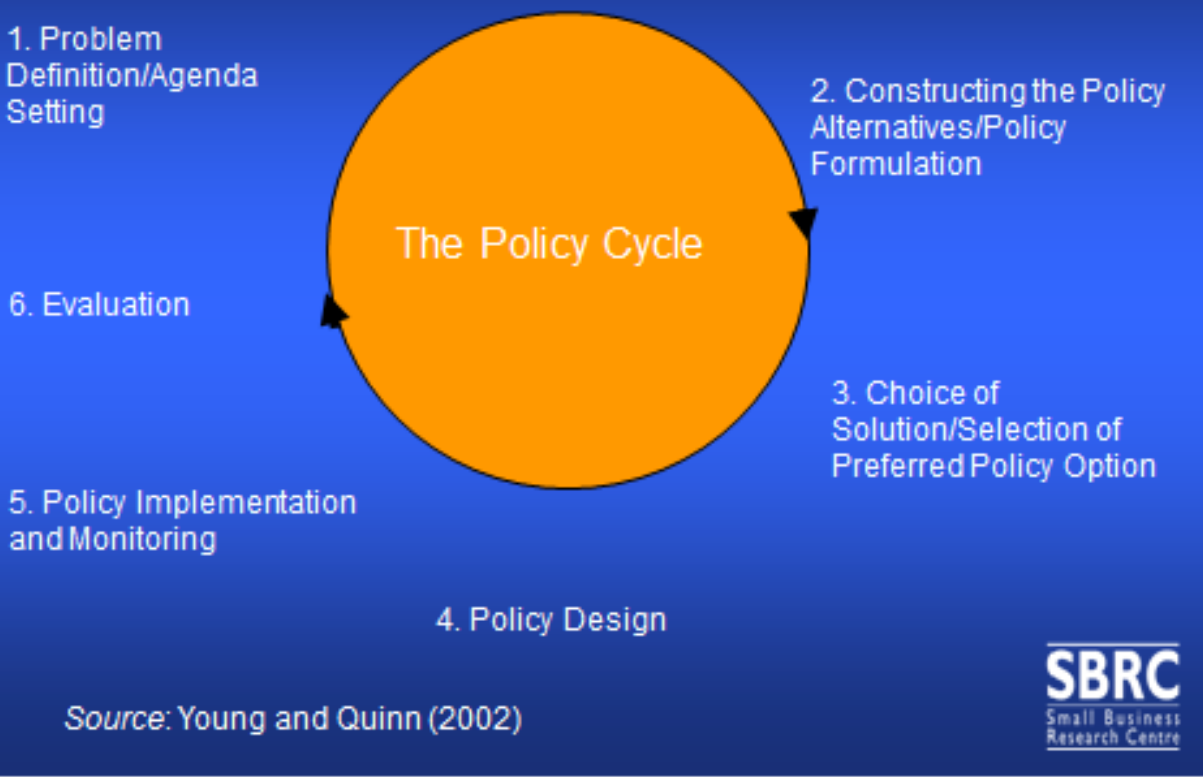

Breaking down the policy process into different stages enables a more analytical approach to be used with regards to the effectiveness of policy, the evidence requirements and policy at different stages, the influence of implementation on the effectiveness of policy and as Arshed et al (2014) emphasises it also draws attention to the process of policy formulation. It is clear that entrepreneurship policy has increasingly been criticised for its lack of effectiveness for which there are different views about the reason. Arshed et al (2014) and others have emphasised the way in which policy is formulated although this particular stage is seldom visible to those outside of government departments and has largely been ignored by previous research. Arshed's ground breaking work was based on a period of internship in the Ministry responsible for SME and entrepreneurship policy development. Her interviews with policy makers indicated that, whilst they are aware of how the formulation process should work ideally, they recognise that, in reality, it is rather different. The period of participant observation led Arshed to the conclusion that the policy process was distinguished by a lack of transparency and a lack of procedure. A key point in Arshed's analysis is the role of what she describes as institutional entrepreneurs who are 'autonomous and reflective agents wreaking havoc on established orders as they create new social entities' (Aldrich 2011). In view of the fact that entrepreneurship literature is predominantly focused on implementation and evaluation (Mole 2002) the formulation stage has largely been ignored, which is where Arshed's study makes a particular contribution. What her internship enabled her to do was not simply to describe the so-called institutional entrepreneur, but to provide detailed descriptions of what they actually do. Arshed's work opens new challenges for future research which includes more 
evidence to better understand the processes involved and the role of key actors, particularly the role of ministers in relation to senior civil servants.

However, it is important to recognise as Arshed has herself that generalisation from the study should be made with extreme caution because any policy needs to be considered in relation to the context in which it is formulated and developed. This particular investigation represents the situation at a specific point in time. Since then the individuals in government have changed as a result of an election and some individuals may have just may been moved to different posts. It is the process that needs to be generalised rather than the detailed content. The other comment to note is that the study was limited to one stage of the overall policy process. One of the intentions is to develop future research and explore more fully other stages of their policy making process, for example, engaging with policy influencers or understanding better the implementation phase. Nevertheless, this research plugs a gap in the policy literature through paying attention to the formulation stage which previously had been relatively neglected.

\section{Policy Issue 3: More explicit attention should be paid to evidence based policy}

Using evidence to inform policy is not a new idea, although it has increased in emphasis in the UK over the last 15 years or so. The term came into greater prominence during the period of the Blair Administration and was intended to indicate the entry of a government with a modernising mandate. Essentially evidence-based policy may be viewed as part of a rational and systematic approach to policy making. It is based on the premise that policy decisions should be better informed by the evidence available rather than just informed opinion (see Figure 3). Although the concept grew in prominence within the UK arguably its significance is particularly important in developing countries where it is typically less well established. It is suggested by some that better utilisation of evidence in policy in practice, can help to reduce poverty and save lives (Sutcliffe \& Court 2005). 


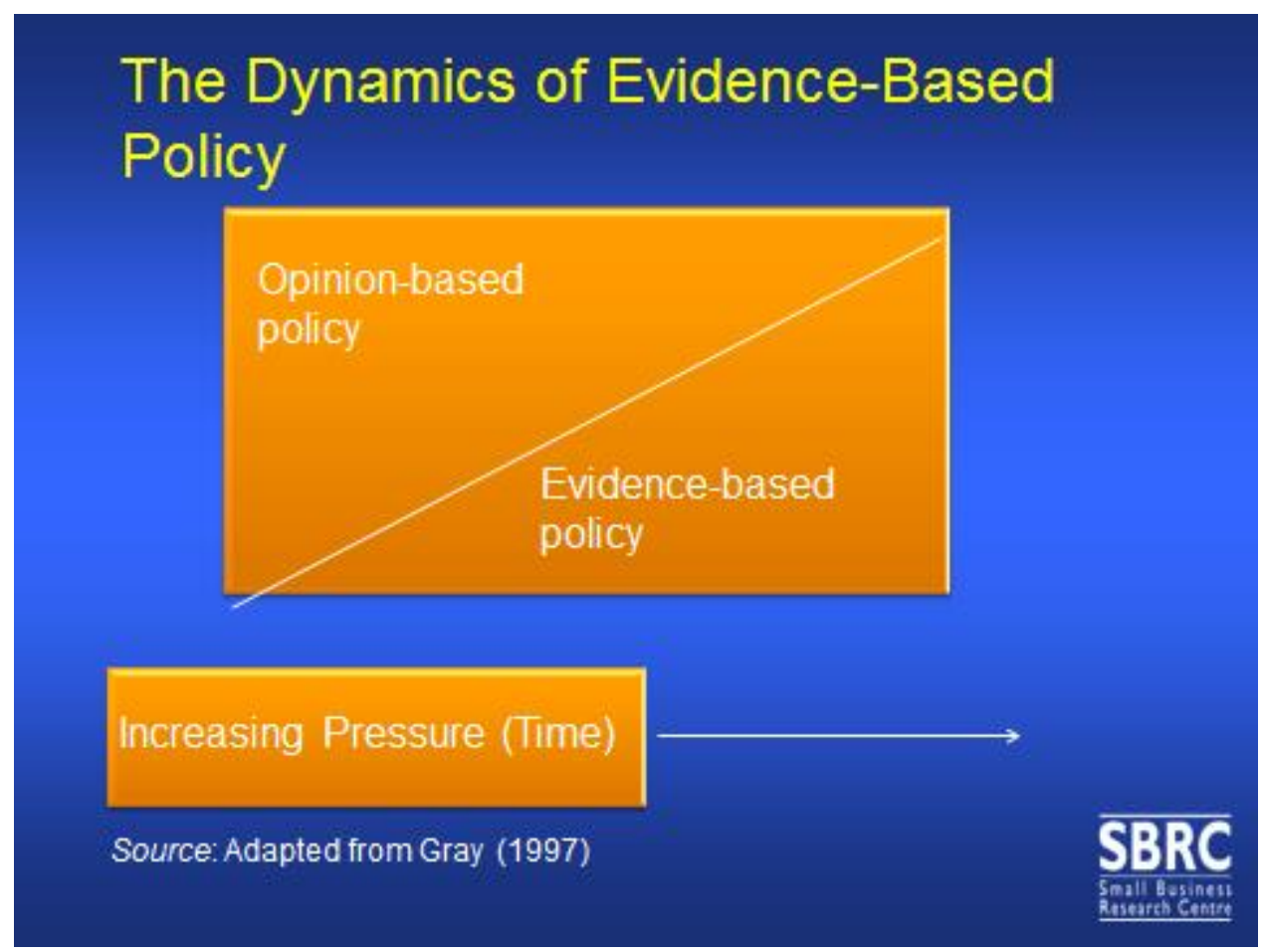

The use of evidence-based policy does raise a number of issues. One is the nature of the evidence that should be used in the policy making process where the literature tends to emphasis the breadth of evidence; combining robust academic research with evidence provided by stakeholder groups and others. The second issue is how evidence is incorporated into policy making. Policy processes typically involve different stages from setting the policy agenda from policy formulation to policy implementation. It may be argued that evidence has the potential to influence the policy making process at each stage, although the evidence used may be different at each of the policy stages and thirdly, evidence is not the only factor which influences policy making. Perhaps the most important point here is that, whilst academics may look for a more logical and rational process, the political pressure is typically to process information quickly, leading to recognition that policy making is neither objective nor neutral. It is a political process.

Sutcliffe and Court (2005) refer to a hierarchy of evidence which means that, although forms of evidence may share equal importance in theory, although in practice they do not. Since not all forms of evidence share equal weighting, attempts have been made to identify the key characteristics of evidence that influence whether or not it is used (Shaxson 2005). The first criteria are quality, accuracy, objectivity. There are issues related to the objectivity of the evidence and its sources. Clearly any bias in the evidence base needs to be identified in order that it can be taken into account in interpreting the evidence for policy. The second criteria is credibility, Shaxson (2005) suggests that credible evidence relies on a strong and clear line of 
argument, tried and tested and analytic methods and analytic rigour throughout the processes of data collection and analysis and also on the conclusions.

In reality it is very difficult for policy makers to check evidence so they tend to rely on the reputation of the sources of proxy. The third criteria are relevance. The key issue here is that evidence is timely, topical and has policy implications. Lastly, practicalities, which relate to the extent to which the evidence is accessible to policy makers and in what form they can access the findings as well as the evidence base.

Figure 4: The flow of evidence in the policy process

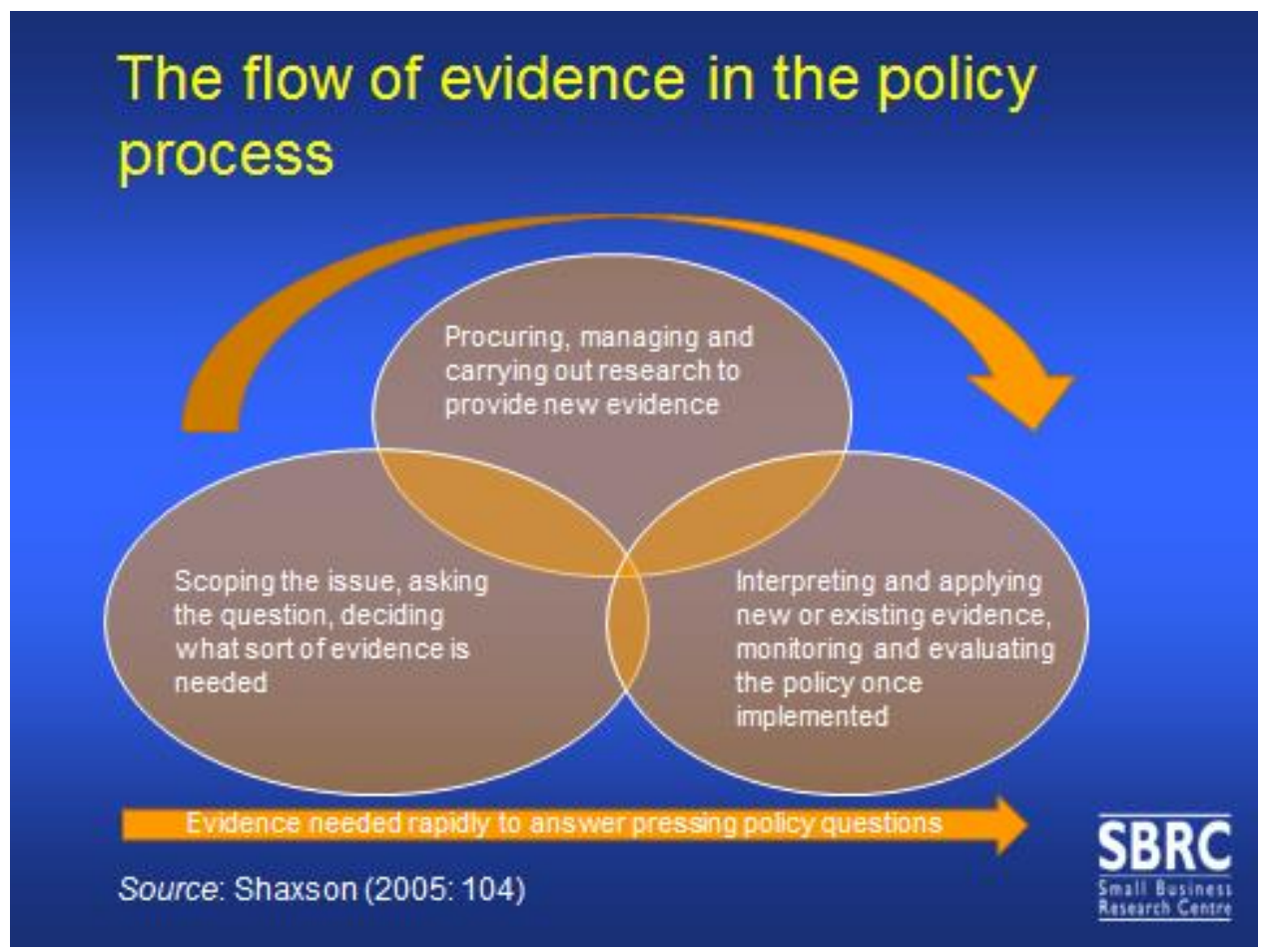

Figure 4 provides a generic description of the flow of evidence in the policy process. Despite its simplistic nature it offers a number of important insights. Firstly, it provides a similar distinction between agenda setting, formulation and monitoring and the different evidence collection processes needed. Secondly, it raises a distinction between evidence needs for pressing policy decisions and those for a longer term strategic policy objectives.

In Table 1 as Sutcliffe \& Court (2005) demonstrate, the nature of the evidence required varies at different stages of the policy process.

Table 1: Components of the policy process and different evidence issues

\begin{tabular}{|l|l|l|}
\hline Stage of the & Description & Different evidence issues \\
\hline
\end{tabular}




\begin{tabular}{|c|c|c|}
\hline policy process & & \\
\hline Agenda setting & $\begin{array}{l}\text { Awareness and priority } \\
\text { given to an issue }\end{array}$ & $\begin{array}{l}\text { Evidence of new problems or the magnitude of a } \\
\text { problem so that relevant policy actors are aware } \\
\text { that the problem is important. A key factor is the } \\
\text { credibility of evidence but also the way evidence } \\
\text { is communicated. }\end{array}$ \\
\hline Formulation & $\begin{array}{l}\text { There are two key stages } \\
\text { to the policy formulation } \\
\text { process: determining the } \\
\text { policy options and then } \\
\text { selecting the preferred } \\
\text { option (see Young and } \\
\text { Quinn, 2002: 13-14) }\end{array}$ & $\begin{array}{l}\text { For both stages, policymakers should ideally } \\
\text { ensure that their understanding of the specific } \\
\text { situation and the different options is as } \\
\text { comprehensive as possible. This includes the } \\
\text { instrumental links between an activity and an } \\
\text { outcome as well as the expected cost and impact } \\
\text { of an intervention. The quantity and credibility of } \\
\text { the evidence is important. }\end{array}$ \\
\hline Implementation & Actual practical activities & $\begin{array}{l}\text { Here the focus is on operational evidence to } \\
\text { improve the effectiveness of initiatives. This can } \\
\text { include analytical work as well as systematic } \\
\text { learning around technical skills, expert } \\
\text { knowledge and practical experience. Pilot } \\
\text { projects are often important. The key is that the } \\
\text { evidence is practically relevant. }\end{array}$ \\
\hline Evaluation & $\begin{array}{l}\text { Monitoring and assessing } \\
\text { the process and impact } \\
\text { or an intervention }\end{array}$ & $\begin{array}{l}\text { The first goal is to develop monitoring } \\
\text { mechanisms. Aa comprehensive evaluation } \\
\text { procedure is essential in determining the } \\
\text { effectiveness of the implemented policy and in } \\
\text { providing the basis for future decision-making. }\end{array}$ \\
\hline
\end{tabular}

Source: Adapted from Poland and Court (2008)

Sutcliffe \& Court (2005) make the point that experience with evidence-based policy in mature market economies cannot be simply transposed into developing countries, which typically have a diverse set of economic, social, economic and political environments, or; whose capacity is more limited; and whose resources are scarcer. As a result, evidence-based policy approaches will need to be adapted if they are to be effectively used in tackling each of the above in turn and beginning with different types of evidence. It may be argued that what counts as evidence varies as much from the researchers work in practice to the end use of the evidence.

One of the reasons why it may be argued that evidence based policy matters, particularly in the field of international development, is because these are fields where the decision maker has 
largely been flying blind, as robust evidence is simply not available. The argument may be applied in the case of entrepreneurship and its contribution to social inclusion; it may also be applied to research on clustering. In both these cases it can be argued that policy has run ahead of the evidence base. Clearly academics have a potential role in relation to public policy to contribute evidence to support or question important policy areas. This certainly applies in the case of entrepreneurship and it also applies in the case of international development.

In the UK, the Regulatory Policy Committee represents an attempt to implement evidencebased policy more systematically than previously. This Committee provides government with external independent scrutiny of evidence supporting changes in law that affect businesses amongst others. The Committee is sponsored by the Department for Business Innovation and Skills (BIS) and comprises eight independent experts drawn from a variety of backgrounds. The Committee was established in 2009 and represents the first body in the UK established to provide independent scrutiny of proposed regulatory measures put forward by government.

The Committee assesses the quality of evidence and analysis supporting regulatory change and its potential impact on businesses. They check the estimated costs or savings to businesses as the result of regulatory reform that is put forward by central government departments. They check that government departments explain new regulation as in comparison with other possible alternatives namely, voluntary codes of practice. When new regulations are required the Committee then checks that government is minimising the effect of any negative impact on small businesses in particular. The approach involves providing opinions on the impact, assessments submitted by the government department responsible. So the underlying rationale for this policy initiative is to seek to ensure that policy and decisions are made on the basis of accurate evidence and the Committee provides advice on the quality of the available evidence.

\section{Policy Issue No. 4: A strengthened commitment should be made to policy evaluation}

Again, using the policy process model as a framework. Another issue requiring more attention in the future is policy evaluation and, in particular, evaluation of policy impacts. Although the UK is often seen as a leader in policy evaluation with the ROAMEF reference (rationale, objectives, appraisal, monitoring, evaluation, methodology) as a blueprint, but in practice it would seem that the limited resources made available to gather evidence as part of policy evaluation means that the systematic implementation of policy evaluation is less than ideal. In practice the emphasis tends to be on fairly low level monitoring, counting numbers in other words, of businesses supported and those growing but without a more rigorous evaluation of policy impact. As far as the actual process of policy evaluation itself is concerned it maybe criticised as being too narrowly based on quantitative approaches when the addition of a qualitative dimension could help to give more insight into how and why a policy can be made more effective. 
Policy evaluation studies have been identified as one of the most rapidly developing areas of entrepreneurship policy related research (Gilbert et al 2004). One of the challenges facing policy evaluators is the diversity of policies that are designed to encourage and support entrepreneurship. These include some that apply to all types of enterprise but also others that are focused on particular types of enterprise, such as firms of particular size range, sector and or growth potential. This diversity also applies to various types of assistance which in some cases, can be very light (such as requests for information) and, in other cases, much more intensive (such as one or more advisory sessions). One of the problems with the former is that often entrepreneurs find it impossible to recall an event that may not have been sufficiently important to them to retain in their memory.

One of the most significant contributions to the field of the policy evaluation studies is the work of David Storey (2000; 2002) whose so-called 'Six Steps to Heaven' has been used to describe and assess the approaches used to undertake monitoring and evaluation of policy. His Six Steps to Heaven start with simple monitoring and end with highly sophisticated evaluation methods. One of the problems with these evaluation studies is the difficulty of finding appropriate data on which to base the evaluation. Whilst government departments may announce their intention to build evaluation into policy design, this is rarely translated on the ground to delivery organisations collecting the kind of information that the policy evaluators require. As a consequence, quite a number of these studies can be criticised because the data are used as a basis for what are often sophisticated econometric methods, do not always look fit for purpose. Storey's Six Steps are summarised as follows. Step 1 is the take up of schemes. Step 2 looks at recipient's opinions about schemes. Step 3 involves recipient's views of the difference made by the assistance they have received. Collectively the first three steps Storey describes as monitoring. Step 4 involves a comparison of the performance of assisted recipients with typical firms. Step 5 involves comparison with matched firms and Step 6 which is the most sophisticated, takes into account selection bias. Steps 4 to 6 Storey describes as evaluation because all of them attempt to determine the economic impact of the policy initiatives.

\section{Policy Issue No 5: Greater attention should be paid to the use of public procurement as a policy tool}

Procurement refers to the acquisition of goods, services or works from an outside external source. It is found in both public and private sectors and, in the latter case, corporations are involved. Corporations and public bodies often define processes intended to promote fair and open competition, whilst minimising exposure to risk. In the UK the most commonly used definition of procurement by UK government departments are taken from the Gerschon review of procurement in central government in 1999. According to Gerschon ( ), procurement refers to the entire process of acquisition from third parties, including the logistical aspects and also covers goods, services, and construction projects. 
Although phi procurement process can involve a number of stages. For exmple, it may include a bidding process known as tendering, and the organisation involved that requires a product or service may set a threshold above which the contract must go out to competitive tendering. The latter is a particular feature with regard to public sector procurement. Such an invitation to tender will contain a statement of what is required by the purchaser. Within the European Union there are strict rules on public procurement which have been set and which public bodies must follow.

Procurement, whether by public sector organisations, or corporations, represents a market opportunity for SMEs. As a consequence, whether or not there is a level playing field with regards to access is an important issue. The EU threshold above which all public contracts are subject to EU rules is important because, for micro-enterprises and for those enterprises that are owned by members of minority groups, it is likely to be the contracts below this threshold that are more likely to be relevant to them. Although procurement contracts represent a market opportunity for small and medium businesses, the problem is that, for the smallest businesses there are typically market deficiencies in the market for procurement contracts; that operates to their disadvantage.

One reason why public procurement warrants attention is its sheer scale. This is easy to understand when one takes into account the fact that public procurement is undertaken by central government departments and ministries, regional authorities, local government, public sector hospitals, schools and so on. Gordon Brown, as former prime minister of the UK, once remarked that if we could increase the procurement contracts going to small and medium-sized businesses by $1 \%$ everything else that we do for small firms would look insignificant.

It has been argued previously that the greatest potential for developing public procurement as a public policy tool lies at the local government level because of the responsibilities that local authorities have for their constituents.

Turning to the question of what type of measures are needed if public procurement is to be more accessible by small and medium enterprises the answer lies in the way that contracts are packaged and specified. A series of government reports have pointed to the need for public bodies to place greater emphasis on community benefits when allocating contracts, for example, the Byerscal government procurement 2001 suggested that promoting best value in community benefits through procurement could be achieved by encouraging councils to engage with a diverse range of suppliers, including small and medium enterprises of all types. In addition the Gershon Report on modernising civil government in 1999 led to the establishment of the Office ofG vernment commerce in the year 2000. Lastly the Glover Report 2008 called for action to reduce barriers to smaller suppliers, including the introduction of a simpler procurement process. 
Issues of Evidence Based Policy has been dealt with essentially as a technical problem.

However, policy making is very much a political process and as Figure 5 suggests, many factors compete with the evidence base to take centre stage in policy formulation. Indeed, it should be noted that some writers think it is a mistake for an evidence based policy approach as this tends to result in the policy process being seen as, essentially, technical issues, which some might see as a mistake, because clearly there is a highly political dimension to it at as well.

\section{Figure 5: Factors influencing policymaking in Government}

\section{Factors influencing policymaking in Government}

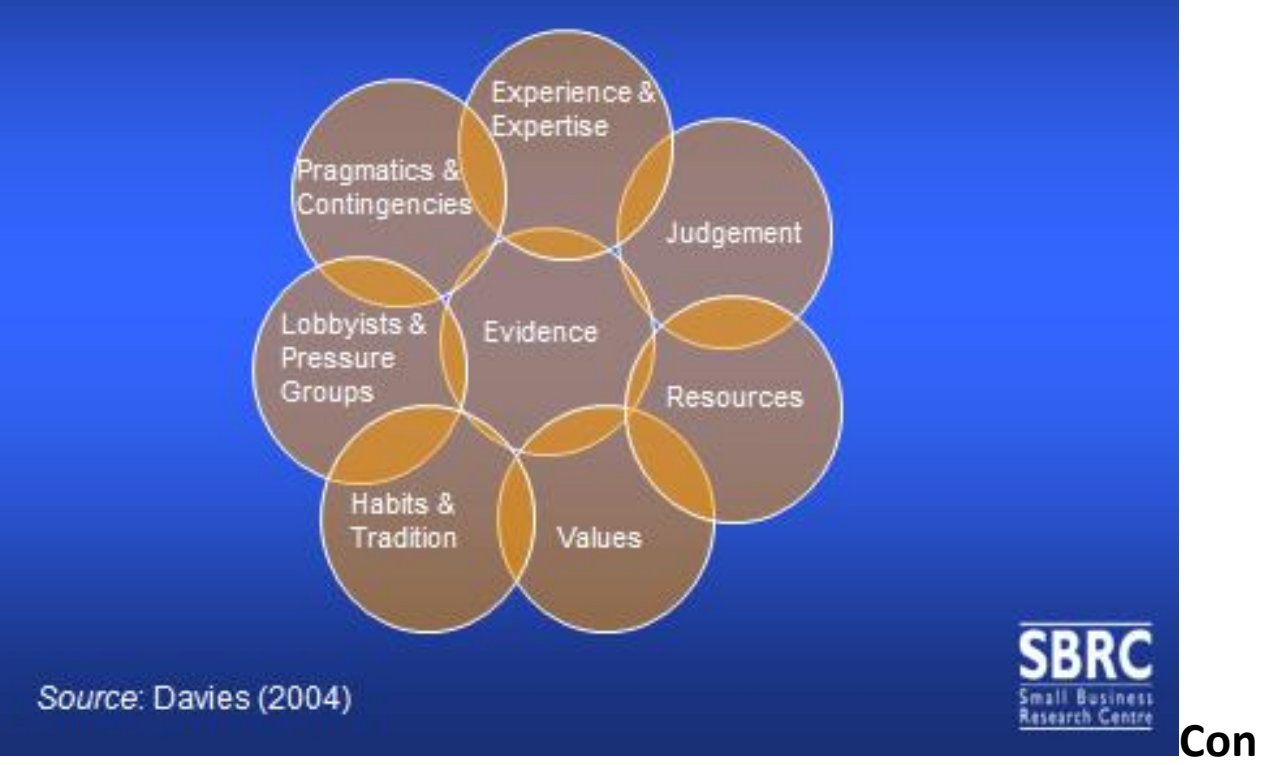

\section{clusions}

It must be stressed that this pa represents work in progress,pparticularly part two of the paper which is concerned with future policy issues and policy priorities. As it stands, the selection of priorities and challenges is rather idiosyncratic, with some major themes left untouched. Targeting is a good example. A key underlying theme in the paper relates to whether or not entrepreneurship policy is necessary and, if so, what form it should take and how it should be delivered our conclusion at this stage of the research is that entrepreneurship policy is not essential to the needs of the economy and of society. However, neither is it a red herring. Context is the key. Many factors influence the role and importance of entrepreneurship policy and, in particular, the level of development and the current level of entrepreneurship development in particular. One of the factors influencing one's answer to this question is 'What is understood by entrepreneurship policy?' In the case of countries where the level of entrepreneurship development is medium to high in international terms, one might suggest 
that the type of entrepreneurship policies described by Lundstrom \& Stevenson (2005) no longer look necessary However, at the same time, it is necessary for government to monitor its own legislation and actions if entrepreneurship is not to be constrained by a regulatory regime that requires a significant effort on the part of businesses to understand and adapt to. So, in other words, one cap does not fit all and differences in context between countries and, in some cases between regions, is essential to understanding the roled importance of entrepreneurship policy. The growth of interest in the policy process reports above should be built upon and become a focus for entrepreneurship policy related research in a way that it has not done so in the past. It has been argued previously that one of the positive influences of EU membership on entrepreneurship policy in the New Member States was the need to recognise and adhere to the EU's agenda; policy makers in New Member States were forced to review the policy process they were contributing to and modify this where necessary. A particular example would be to link explicit strategy with an action plan and, most importantly with a budget. This has helped to address what previously had been a significant problem in these countries; a so-called implementation gap.

In addition, research on the policy process could provide a focus for other aspects of what is suggested in this paper; for a stronger commitment to evidence based policy for example. One of the issues that some people who read in this paper will be thinking is, where does this leave academic researchers interested in public policy; what are the implications for the nature and extent of their contribution. In this regard one might suggest that, in the past, there has been too much emphasis by conference chairs and organising committees in particular, but also some journals, where scientific or academic researchers were forced to draw out public policy implications even if these were not part of the original research design, nor, indeed, an aspect which interested them, but they felt necessary to get their paper accepted. My own view is that forcing researchers to think about implications for policy in this instance, where public policy was never really built into the methodology, looks a rather dangerous activity, particularly when one considers some of the implications and recommendations that emerge from this. In other words they are clearly written by people that have got little understanding of policy making, nor, indeed a great deal of interest in it.

Another underlying theme emerging from the review concerns the limited use by entrepreneurship policy researchers of developments in other policy areas. This is a mistake because, in some cases, issues or topics are coming onto the agenda for entrepreneurship policy rave been analysed and discussed by colleagues in other policy areas in the past. This is exactly what happened in the case of a study of mainstreaming undertaken by Blackburn \& Smallbone (2008). This study was concerned with the circumstances in which a group of policy measures that had been developed and implemented in the case of a targeted initiative (often an EU funded initiative) and the extent to which such measures could be mainstreamed; in the sense of being rolled-out across the country as a whole, and, if so, what conditions it was necessary to fulfil to influence its effectiveness. The only research for this study showed that, ten years previously, very similar questions would have been asked in relation to social policy and health policy. Whilst the context may be different clearly there are potential dangers in 
following this kind of line too narrowly. Nevertheless, in viewing some of the factors influencing from the health and social policy area, we found remarkably similar discussions and applications. In this regard, this is an area which needs to be given more attention to in the future as another business policy transfer fieldwhist emphasising paying attention to differences in context. 


\section{References}

Aldrich, H. E. (2011). Heroes, villains and fools: Institutional entrepreneurship, not institutional entrepreneurs. Entrepreneurship Research Journal, 1(2), 1-6

Arshed, N., Carter, S., \& Mason, C. (2014) The ineffectiveness of entrepreneurship policy: is policy formulation to blame? Small Business Economics, 43, 639-654

Atherton A. and Smallbone D. (2013) Promoting private sector development in China - the challenge of building institutional capacity at the local level. Environment and Planning $C$, Government and Policy, 31, 1, 5-23

Bennett, R. (2008) SME Policy Support in Britain since the 1990s: What Have We Learnt? Environment and Planning C: Government and Policy, 26(2), 375-97

Blackburn, R., and Smallbone, D., (2008) Researching small firms and entrepreneurship in the UK: Developments and distinctiveness. Entrepreneurship Theory and Practice, 322, 267-288

Curran, J., \& Storey, D. J. (2002) Small business policy in the United Kingdom: The inheritance of the Small Business Service and implications for its future effectiveness. Environment and Planning C: Government and Policy, 20(2), 163-177Davies (2004) Is evidence-based government possible? Jerry Lecture presented at the $4^{\text {th }}$ Annual Campbell Collaboration Colloquium, Washington DC

Dennis, Jr., W. J. (2011), Entrepreneurship, small business and policy levers. Journal of Small Business Management, 49(1), 92-106 Gray, J.A.M. (1997) Evidence-Based Healthcare: How to Make Health Policy and Management Decisions. New York, Edinburgh, London, Churchill Livingstone

Gerschon ( )

Gilbert, B., Audretsch, D. B., \& McDougall, P.P. (2004). The emergence of entrepreneurship policy. Small Business Economics, 22(3-4), 313-323

Huggins, R. \& Williams, N. (2009) Enterprise and public policy: A review of Labour government intervention in the United Kingdom. Environment and Planning C: Government and Policy, 27(1), 19-41

Kitching, J. (2006) A burden on business? Reviewing the Evidence Base on Regulation and SmallBusiness Performance. Environment and Planning C: Government and Policy, 24(6), 799-814

Lundstom, A., \& Stevenson, L.A., (2005) Entrepreneurship policy: Theory and Practice. Springer 
Mole, K., (2002) Business Advisers' Impact on SMEs: An Agency Theory Approach. International Small Business Journal, 20(2), 139-60

Pollard, A. \& Court, J. (2005) How Civil Society Organisations Use Evidence to Influence Policy Processes: A literature review. ODI Working Paper 249, London, ODI

Scott, S., (2009) Why encouraging more people to become entrepreneurs is bad public policy. Small Business Economics, 33(2), 141-149

Shaxson, L. (2005) Is your evidence robust enough? Questions for policy makers and practitioners. Evidence and Policy: A Journal of Research, Debate and Practice, 1(1), 101-111

Smallbone D., Xiao Jianzhong and Xu Lei (2008) 'Developing the Small Business Market for Business Development Services in Chengdu: Policy Issues and Priorities', Journal of Small Business and Enterprise Development 15, 4, 656-674

Smallbone, D. \& Welter, F. (2001) The Role of Government in SME Development in Transition Countries. International Small Business Journal, 19(4), 63-77, ISSN 0266-2426

Sutcliffe, S. \& Court, J. (2005) Evidence based policy making: What is it? How does it work? What relevance for developing countries? Overseas Development Institute

Storey, D. J. (2002) Methods of Evaluating the Impact of Public Policies to Support Small Businesses: The Six Steps to Heaven. International Journal of Entrepreneurship Education, 1(2), 181-202

Storey, D.J. (2000) Six steps to heaven: Evaluating the impact of public policies to support small businesses in developed economies. In L. Sexton \& H. Landstrom (Eds.). The Blackwell handbook of entrepreneurship, Great Britain, Blackwell Publishers Ltd

Van Stel, A., Storey, D.J. \& Thurik, A. (2007) The effect of business regulations on nascent and young business entrepreneurship. Small Business Economics, 28(2), 171-186

Welter, F. (2011) Contextualising Entrepreneurship: Conceptual Challenges and the Way Forward. Entrepreneurship Theory and Practice, 35(1)

Williams, N. (2013) Entrepreneurship and the role of policy. Environment and Planning C: Government and Policy, 31(1), 1-4 
Xheneti, M. \& Kitching, J.(2011) From discourse to Implementation: Enterprise Policy

Development in Post Communist Albania. Environment and Planning C; Government and Policy 29(6), 1018-1036

Young, E. \& Quinn, L. (2002) Writing Effective Public Policy Papers: A Guide to Policy Advisers in Central and Eastern Europe, Budapest: LGI 